\title{
EFFECT OF HIGH FREQUENCY REPETITIVE TRANSCRANIAL MAGNETIC STIMULATION OF THE CONTRALESIONAL MOTOR CORTEX ON RECOVERY FROM POST-STROKE SEVERE MOTOR IMPAIRMENT
}

By

\author{
Esam Mahdy Ibrahim ${ }^{1}$, Mohamed Ahmed Zaki ${ }^{2}$, and Mohamed Gaber \\ Mahmoud Gabr ${ }^{1 *}$
}

Departments of Neurology, Faculty of Medicine, Al-Azhar University, Damietta ${ }^{1}$, Cairo $^{2}$, Egypt

*Corresponding author: Mohamed Gaber Mahmoud Gabr,

E-mail: gaber.neurology@gmail.com

\begin{abstract}
Background: The traditional inhibition of contralesional primary motor area (cM1) with low frequency repetitive transcranial magnetic stimulation (rTMS) fails to improve post-stroke severe motor impairment. The role of contralesional motor areas in post-stroke motor recovery is still questionable. While the previous data suggested that cM1 exerts transcallosal inhibitory effect on ipsilesional M1 (iM1) following stroke, there isan evidence that contralesional motor areas, particularly the contralesional dorsal premotor area (cPMd), have compensatory roles in severely impaired patients who have extensive ipsilesional damage.
\end{abstract}

Objectives: To study whether facilitating cPMd with high frequency rTMS as a novel approach, instead of conventionally suppressing $\mathrm{cM} 1$, has beneficial effect on motor recovery of post-stroke severely impaired upper extremity (UE) or not.

Patients and Methods: Forty right handed, first ever stroke patients ( 3 months post event) with severe stroke symptoms, severe motor deficit, and radio logically evident massive right cerebral infarctions at baseline were randomly assigned to two equal groups, to receive, as adjunct to ordinary rehabilitation techniques, ten consecutive sessions of either: (1) High frequency rTMS at $5 \mathrm{~Hz}$ on cPMd; or (2) Sham rTMS. The Medical Research Council (MRC) for muscle strength and UE- Fugl Meyer Assessment (UE-FMA) were assessed before and after the intervention.

Results: By using the one way analysis of covariance (ANCOVA), we found significant improvements in grand means of MRC in the active rTMS group in relation to the sham group. The improvements included in particular the mean proximal MRC, whereas no significant improvement in the mean distal MRC. Similarly, we found that the UE-FMA totals were markedly improved in the active group in relation to the sham group, mainly in the proximal UE-FMA. Stepwise regression showed that lower baseline MRC of the affected UE muscles is an independent predictor of better response to the novel rTMS approach.

Conclusion: Applying high frequency rTMS to cPMd can improve motor functions of the disabled UE, mainly proximal functions, in more severely impaired stroke patients.

Keywords: Contralesional, High Frequency, Repetitive Transcranial Magnetic Stimulation, Stroke, Severe Motor Impairment 


\section{INTRODUCTION}

Stroke is a leading cause of mortality and a long-term disability worldwide. Despite the current downswing in the incidence worldwide, the prevalence of stroke and its long term sequels are still increasing over time and the number of post-stroke survivors worldwide exceeded the 80 million (Gorelick, 2019). Contralateral hemiparesis is the most prevalent neurological deficit occurs after stroke, accounting for more than $80 \%$ acutely, and more than $40 \%$ chronically (Hatem et al., 2016).

New era in neuro-rehabilitation has been started with the emergence of noninvasive brain stimulation (NIBS) as a new neuro-rehabilitation tool that can be used as adjunctive to the traditional techniques. The last decade has been reported to have an increasing interest in using NIBS in the different domains neuro-rehabilitation (Finisguerra et al., 2019). The current methods of NIBS in post-stroke motor rehabilitation is to facilitate iM1 with high frequency rTMS or anodal transcranial direct current stimulation, or, relying on post-stroke transcallosal interhemispheric inhibition (IHI), to suppress the cM1 with low frequency rTMS or cathodal transcranial direct current stimulation (Hatem et al., 2016).

The healthy human brain has a crossinhibition relationship between motor areas of both hemispheres. Each M1 has inhibitory effect towards the other one via transcallosal fibers. This is known as IHI, and is thought to play a crucial role during the intended unilateral voluntary hand movements through preventing the involuntary mirrored movements of the non-intended hand (Genc et al., 2015). The IHI can be assessed functionally with TMS through measurement of the ipsilateral silent period, which is defined as momentary disruption in EMG activity after applying single pulse TMS to M1 during ipsilateral volitional movements, and is thought to be mediated through IHI (Hübers et al., 2019).

After brain insult such as stroke, the cross-inhibition between M1 of both hemispheres may be shifted out of balance. Because iM1 may lose its inhibitory drive on cM1, cM1 is more activated and exerts more inhibition on cM1. Relying on that, one of the currently used NIBS techniques in post-stroke motor rehabilitation is to inhibit cM1 (Boddington and Reynolds, 2017).

The previous trials found no considerable benefit from using the current techniques of NIBS in severe poststroke motor disability (Cunningham et al., 2015). On the other side, inhibition of cM1 may be associated adverse effects. Takeuchi et al. (2012) found that applying low frequency rTMS to contralesional motor areas interferes with bimanual motor coordination in post-stroke survivors. The other major concern is that uncrossed corticospinal pathway of the unaffected side may be recruited in recovery of severe stroke (Alawieh et al., 2017), so inhibiting the contralesional motor cortex could interfere with motor recovery of severe cases.

Di pino et al. (2014) have proposed a new concept regarding the role of contralesional hemisphere in post-stroke recovery; the bimodal balance-recovery model. They launched a new term, structural reserve, to describe the 
remaining ipsilesional functional motor output, and determine the effect of contralesional hemisphere on iM1. With good structural reserve, the IHI model will predominate. Therefore, cM1 will suppress iM1. In contrast, with poor structural reserve, the contralesional motor areas, specifically cPMd, will compensate for the ipsilesional lost functions.

The present work aimed to study the effect of facilitating the cPMd as a novel approach, instead of suppressing cM1, on motor recovery of severely impaired stroke patients.

\section{SUBJECTS AND METHODS}

A randomized double-blinded shamcontrolled study was conducted in 40 right handed patients between the ages of 40 and 70 years old, who developed first ever ischemic stroke and had severe baseline stroke symptoms; the National Institute of Health Stroke Scale (NIHSS) $\geq 15$ (Walcott et al., 2014), post-stroke severe left UE paresis; the MRC for muscle strength $\leq 1$ (Hendricks et al., 2002), and radiologically-evident massive right cerebral infarction; infarct volume $\leq 60$ $\mathrm{mL}$. The massive infarct volume cut-off was based on previous reports (Walcott et al., 2014). The study compared the effect of applying either high-frequency rTMS or sham rTMS to cPMd three months post event, as adjunctive therapies to outpatient ordinary rehabilitation techniques, on the recovery from severe motor impairment.

\section{Exclusion criteria:}

1. Concomitant head injury or neurological illness.
2. Patients who were expected not to complete the study or to be cooperative during the study (e.g. altered consciousness, bad general condition and cognitive impairment "Minimental State Examination $<24$ ").

3. Contraindication to rTMS (e.g. unstable arrhythmias, epilepsy, presence of intracranial ferromagnetic material " e.g. cochlear implant, or presence of cardiac pacemaker).

4. Inability to give consent.

The study was passed through the following phases:

Phase (1): Baseline assessment and patient selection ( 3 days post event):

452 stroke patients were enrolled in the initial assessment. They were subjected to the following:

1. Complete clinical assessment.

2. Assessment of stroke severity using the NIHSS.

3. Assessment of the affected UE motor power, using the MRC Scale.

4. Brain MRI: for assessment of brain infarction including volume measurement.

5. Measurement of motor threshold and TMS induced Motor Evoked Potentials (MEPs) of iM1.

After completing this phase, 54 patients fulfilled the study criteria, while 398 patients were excluded. From the selected 54 patients, 8 patients died, 6 patients refused to give consent. The remaining 40 passed to the next phase after giving a written consent. The study goals were explained to all of them before giving the consent. All the selected 


\section{ESAM MAHDY IBRAHIM et al.,}

patients underwent a unified rehabilitation program and were given an appointment for the next study phase.

\section{Phase (2): Assessment of the studied patients before applying rTMS (3 months post event):}

The studied patients $(\mathrm{N}=40)$ were subjected to the following:

1. Assessment of the MRC scale for muscle strength of the paralyzed UE.

2. Measurement of the paralyzed UEFMA. The UE-FMA scores (total scores: 0-66) were divided in to proximal (0-42 points) and distal (0-24 points) (Lee et al., 2015).

\section{Phase (3): rTMS application:}

The studied patients were randomly divided into two equal groups:

1. Active rTMS group: were submitted to 10 consecutive sessions of high frequency rTMS on the cPMd.

2. Sham rTMS group: were submitted to 10 consecutive sessions of sham rTMS.

The rTMS was delivered using The Magstim ${ }^{\circledR}$ Rapid $^{2}$ system with a $70 \mathrm{~mm}$ figure-of-eight uncoated flat coil. Sham rTMS was delivered using a sham Magstim coil that delivers only 5\% of the stimulator output (Magstim Company, UK). The stimulator was producing a maximum output of 3.5Tesla at the coil surface (output type: biphasic; pulse width: $400 \mu \mathrm{s})$. It was used for stimulation at a frequency of $5 \mathrm{~Hz}$. Each train of pulses consisted of five single pulses with an interstimulus interval of $100 \mathrm{~ms}$, thus lasting for $400 \mathrm{~ms}$. A clicking sound was produced mechanically by the sham coil with each TMS pulse. The stimulator was set to $40 \%$ of the maximum stimulator output during sham stimulation, with sound level of $87 \mathrm{~dB}$. The sound level of the active coil at $80 \%$ of the maximal stimulator output (MSO) setting (the highest settings) was $86 \mathrm{~dB}$.

By using the EEG 10-20 system, right M1 and right PMd were identified. Right M1 was located at $20 \%$ of the distance from $\mathrm{Cz}$ to right $\mathrm{A} 2$, beginning the measurement at $\mathrm{Cz}$. Right $\mathrm{PMd}$ was defined relative to M1 position. We calculated $8 \%$ of the distance from nasion to inion (typically about $3 \mathrm{~cm}$ ), and defined the PMd area as being located at the same distance anterior to M1.

MEP pod was connected to the machine universal interface, where the EMG surface electrode was attached to it. The TMS motor threshold (MT) was determined for each subject as the lowest intensity of the MSO necessary to elicit a visible contraction of the contralateral thumb or fingers or at least $50 \mu \mathrm{V}$ peak-to peak amplitude of MEP contralateral to single TMS pulses delivered over the M1 in at least 5 of 10 trials.

\section{Phase (4): Assessment of patients one week after applying the rTMS:}

The two groups were subjected to:

1. Reassessment of MRC of the paralyzed UE.

2. Reassessment of the paralyzed UEFMA.

\section{Ethical Considerations:}

The study protocol was approved by the Ethics Committee of Al-Azhar Faculty of Medicine on April 2015. The study was performed in accordance with the ethical standards laid down in the 1964 
Declaration of Helsinki and its later amendments.

\section{Statistical Analysis:}

Statistical analysis was done using SPSS for windows version 21 (IBM Corp. Armonk, NY, USA). The study groups were compared as regard to demographic characteristics, stroke risk factors, and baseline assessment, using unpaired t test for continuous variables normally distributed and the Mann-Whitney test for abnormally distributed continuous variables, whereas chi-squared test was used for categorical variables. One way analysis of covariance (ANCOVA) was used to compare post-intervention scores of the used measures between the two groups after controlling for the difference in the pre-intervention scores. Pearson correlation coefficient and Stepwise linear regression were done within the active rTMS group to find the best predictive model of good response to the novel rTMS approach, using baseline measures of motor impairment (MRC, and TMSinduced MEPs amplitude of iM1) as independent variables, and the change scores in the outcome measures (MRC and UE-FMA) as dependent variables. Multicollinearity among the independent variables was excluded by the variance inflation factor (VIF) of 1 . All the used statistical tests were done with significance at $\mathrm{P}<0.05$.

\section{RESULTS}

\section{Demographic characteristics and stroke risk factors:}

Both the active and sham rTMS groups were comparable as regard to the demographic characteristics and the stroke risk factors. The mean age of the active group was $58.70 \pm 5.58$ years, while that of the sham group was $60.20 \pm 5.33$ years. We found that $65 \%$ of the active group patients were males and $35 \%$ were females, while the other group included $55 \%$ males and $45 \%$ females. The mean weight of the active and sham group patients were $89.9 \mathrm{~kg}$ and $87.6 \mathrm{~kg}$ respectively, while the mean heights of the two groups was $170.6 \mathrm{~cm}$ and 168.9 $\mathrm{cm}$ in the same order. The mean body mass index was $31.12 \pm 3.03$ in the active rTMS group, and $30.70 \pm 2.61$ in the sham group. The majority of the active group patients $(70 \%)$ were educated, while only
$45 \%$ the other group were educated. We found also that $80 \%$ of the active group patients were diabetic, while frequency of diabetes in the sham group was 55\%. $60 \%$ of the active group were hypertensive, while frequency of hypertension in the sham group was $70 \%, 45 \%$ of the active group were smokers, while frequency of smoking in the sham group was 30\%, 95\% of the active group were dyslipidemic, while frequency of dyslipidemia in the sham group was $85 \%, 70 \%$ of the active group were obese, while frequency of obesity in the sham TMS group was 55\%, $15 \%$ of the active group were cardiac patients, while frequency of heart disease in the sham group was 35 . There were no significant statistical differences between the two groups as regard to all mentioned risk factors and demographic characteristics $(\mathrm{P}>0.05)$ (Table.1). 
Table (1): Comparison between the studied groups as regard to general characteristics and stroke risk factors

\begin{tabular}{|c|c|c|c|c|}
\hline \multicolumn{2}{|c|}{ Demographic data $\quad$ Groups } & Active TMS & $\begin{array}{l}\text { Sham TMS } \\
\text { group }\end{array}$ & $\begin{array}{c}P \\
\text { value }\end{array}$ \\
\hline \multicolumn{2}{|c|}{ Age(years)(mean \pm SD) } & $58.70 \pm 5.58$ & $60.20 \pm 5.33$ & 0.390 \\
\hline Sex & $\begin{array}{l}\text { Male } \\
\text { Female }\end{array}$ & $\begin{array}{c}13(65 \%) \\
7(35 \%)\end{array}$ & $\begin{array}{l}11(55 \%) \\
9(45 \%)\end{array}$ & 0.519 \\
\hline \multicolumn{2}{|c|}{ Weight $(\mathrm{Kg})($ mean $\pm \mathrm{SD})$} & $89.90 \pm 9.18$ & $87.55 \pm 7.53$ & 0.382 \\
\hline \multicolumn{2}{|c|}{$\operatorname{Height}(\mathrm{Cm})($ mean $\pm \mathrm{SD})$} & $170.75 \pm 4.14$ & $168.90 \pm 3.31$ & 0.127 \\
\hline \multicolumn{2}{|c|}{$\begin{array}{l}\text { Body Mass Index }(\mathrm{Cm})(\text { mean } \pm \\
\text { SD) }\end{array}$} & $31.12 \pm 3.03$ & $30.70 \pm 2.61$ & 0.642 \\
\hline Education & $\begin{array}{l}\text { Educated } \\
\text { Non-educated }\end{array}$ & $\begin{array}{c}14(70 \%) \\
6(30 \%)\end{array}$ & $\begin{array}{c}9(45 \%) \\
11(55 \%)\end{array}$ & 0.110 \\
\hline Diabetes & $\begin{array}{l}\text { Positive } \\
\text { Negative }\end{array}$ & $\begin{array}{l}16(80 \%) \\
4(20 \%)\end{array}$ & $\begin{array}{l}11(55 \%) \\
9(45 \%)\end{array}$ & 0.176 \\
\hline Hypertension & $\begin{array}{l}\text { Positive } \\
\text { Negative }\end{array}$ & $\begin{array}{l}12(60 \%) \\
8(40 \%)\end{array}$ & $\begin{array}{c}14(70 \%) \\
6(30 \%)\end{array}$ & 0.507 \\
\hline Smoking & $\begin{array}{l}\text { Positive } \\
\text { Negative }\end{array}$ & $\begin{array}{c}9(45 \%) \\
11(55 \%)\end{array}$ & $\begin{array}{c}6(30 \%) \\
14(70 \%)\end{array}$ & 0.327 \\
\hline Dyslipidemia & $\begin{array}{l}\text { Positive } \\
\text { Negative }\end{array}$ & $\begin{array}{c}19(95 \%) \\
1(5 \%)\end{array}$ & $\begin{array}{c}17(85 \%) \\
3(15 \%)\end{array}$ & 0.292 \\
\hline Obesity & $\begin{array}{l}\text { Positive } \\
\text { Negative }\end{array}$ & $\begin{array}{l}14(70 \%) \\
6(30 \%)\end{array}$ & $\begin{array}{l}11(55 \%) \\
9(45 \%)\end{array}$ & 0.327 \\
\hline Heart Disease & $\begin{array}{l}\text { Positive } \\
\text { Negative }\end{array}$ & $\begin{array}{l}3(15 \%) \\
17(85 \%)\end{array}$ & $\begin{array}{l}7(35 \%) \\
13(65 \%)\end{array}$ & 0.144 \\
\hline
\end{tabular}

\section{Baseline assessment:}

Both the active and the sham rTMS groups were comparable as regard to the baseline assessment using Mann Whitney U test. Clinically, no significant statistical difference was found between NIHSS of both groups $(\mathrm{P}=0.102)$. Similarly no significant statistical differences between the grand mean MRC $(\mathrm{P}=0.547)$. Radio logically, the infarct volume was also comparable in both groups () (Table. 2). Lastly, no significant statistical difference was found regarding the TMS-induced MEPs amplitudes of both groups. 
Table (2): Baseline clinical, radiological and electrophysiological characteristics of the study groups

\begin{tabular}{|c|c|c|c|c|}
\hline \multicolumn{2}{|c|}{$\begin{array}{ll} & \text { Groups } \\
\text { Assessment measures }\end{array}$} & Active TMS & Sham TMS group & $\begin{array}{c}P \\
\text { value }\end{array}$ \\
\hline \multicolumn{2}{|c|}{ Baseline NIHSS } & $20.0(18.25-22.75)$ & $18.5(18.25-22.75)$ & 0.102 \\
\hline \multirow{7}{*}{$\begin{array}{l}\text { Baseline } \\
\text { MRC }\end{array}$} & Fingers & $00.0(00.0-1.00)$ & $0.00(0.00-1.00)$ & 0.799 \\
\hline & Wrist & $00.0(00.0-1.00)$ & $1.00(0.00-1.00)$ & 0.602 \\
\hline & Mean distal & $00.5(00.0-0.88)$ & $0.50(0.00-1.0)$ & 0.583 \\
\hline & Elbow & $00.5(00.0-1.00)$ & $1.00(0.00-1.00)$ & 0.602 \\
\hline & Shoulder & $01.0(00.0-1.00)$ & $1.00(0.250-1.00)$ & 0.799 \\
\hline & Mean proximal & $00.5(0.125-1.00)$ & $0.50(0.13-1.00)$ & 0.547 \\
\hline & Grand mean & $0.38(0.25-0.75)$ & $0.75(0.25-1.00)$ & 0.547 \\
\hline \multicolumn{2}{|c|}{ Baseline infarct volume $(\mathrm{mL})$} & $161.5(132.5-195.2)$ & $136.5(106.0-174.3)$ & 0.134 \\
\hline \multicolumn{2}{|c|}{$\begin{array}{l}\text { Baseline TMS-induced MEP } \\
\text { amplitude of iM1 }(\mu \mathrm{V})\end{array}$} & $0.8(0.60-1.18)$ & $1.10(0.83-1.30)$ & 0.081 \\
\hline
\end{tabular}

Pre- and post rTMS motor assessment:

Assessments of muscle power and motor performance of the affected UE, using the MRC and UE-FMA respectively, were performed before and after rTMS application. Descriptive statistics for the measured scores are demonstrated in (Table 3). By using onway ANCOVA, we found significant improvements of the MRC and UE-FMA scores in the active group as compared to the sham group, mainly in the proximal domain. (Table. 4) There was significant improvements in grand means of MRC in the active rTMS group in relation to the sham group $(\mathrm{F}=56.093, \mathrm{P}<0.0005$, Partial $\eta 2=0.603$ ) (Figure4A). The improvement includes in particular the mean proximal MRC $\quad(\mathrm{F}=85.551, \quad \mathrm{P}<0.0005, \quad$ Partial $\eta 2=0.698$ ) (Figure4B), no significant improvement in the mean distal MRC $(\mathrm{F}=6.380, \quad \mathrm{P}=0.016, \quad$ Partial $\eta 2=0.147)$ (Figure4C). Similarly, we found that the UE-FMA totals were markedly improved in the active group in relation to the sham group $(\mathrm{F}=130.331, \quad \mathrm{P}<0.0005, \quad$ Partial $\eta 2=0.779$ ) (Figure.4D), mainly in the proximal UE-FMA $(\mathrm{F}=169.915$, $\mathrm{P}<0.0005$, Partial $\eta 2=00.821$ ) (Figure.4E), whereas no significant improvement in the distal UE-FMA $(\mathrm{F}=3.030, \quad \mathrm{P}=0.090$, Partial $\eta 2=0.076$ ). (Figure (4 F).

Table (3): Descriptive statistics for pre- and post-rTMS motor assessment (MRC and UE-FMA - Meam+sd.

\begin{tabular}{|l|l|c|c|c|c|}
\hline \multirow{2}{*}{$\begin{array}{l}\text { Assessment } \\
\text { Measures }\end{array}$} & \multicolumn{2}{|c|}{ Active rTMS group } & \multicolumn{2}{c|}{ Sham rTMS group } \\
\cline { 2 - 6 } & Pre-rTMS & Post-rTMS & Pre-rTMS & Post-rTMS \\
\hline \multirow{3}{*}{ MRC } & Mean distal & $1.20 \pm 0.44$ & $1.40 \pm 0.48$ & $1.40 \pm 0.50$ & $1.43 \pm 0.47$ \\
\cline { 2 - 6 } & $\begin{array}{l}\text { Mean } \\
\text { proximal }\end{array}$ & $1.80 \pm 0.50$ & $4.00 \pm 0.81$ & $1.78 \pm 0.44$ & $1.95 \pm 0.60$ \\
\cline { 2 - 6 } & Grand total & $1.50 \pm 0.44$ & $2.70 \pm 0.44$ & $1.59 \pm 0.45$ & $1.79 \pm 0.50$ \\
\hline \multirow{2}{*}{$\begin{array}{l}\text { UE- } \\
\text { FMA }\end{array}$} & Distal & $1.30 \pm 2.13$ & $2.20 \pm 3.29$ & $2.00 \pm 3.08$ & $2.35 \pm 3.63$ \\
\cline { 2 - 6 } & Proximal & $16.85 \pm 2.92$ & $31.65 \pm 4.09$ & $15.30 \pm 3.05$ & $15.95 \pm 3.44$ \\
\cline { 2 - 6 } & Total & $18.15 \pm 4.43$ & $33.85 \pm 5.28$ & $17.30 \pm 5.68$ & $18.30 \pm 6.59$ \\
\hline
\end{tabular}


(A)

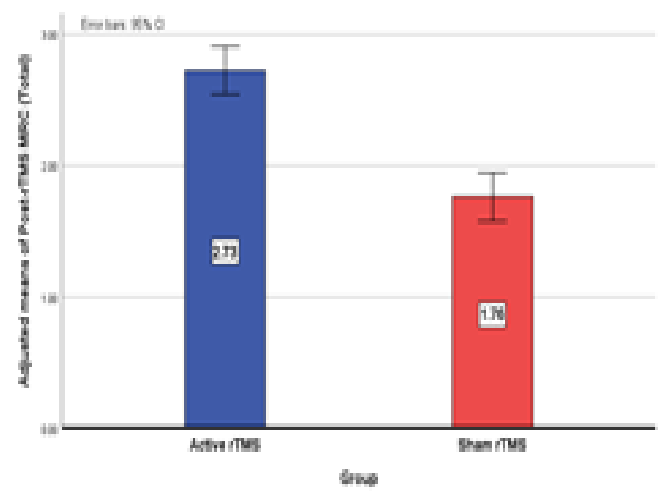

(C)

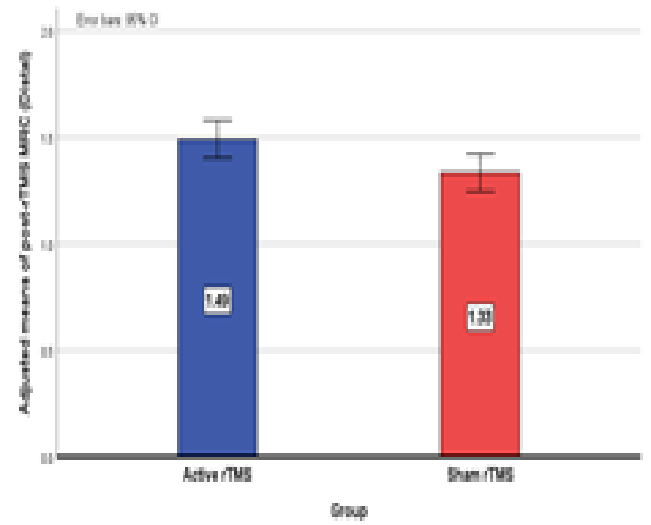

(E)

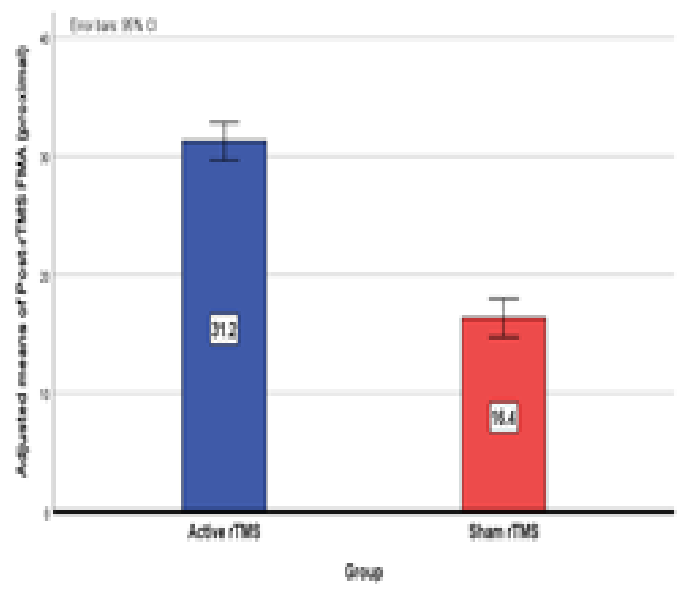

(B)

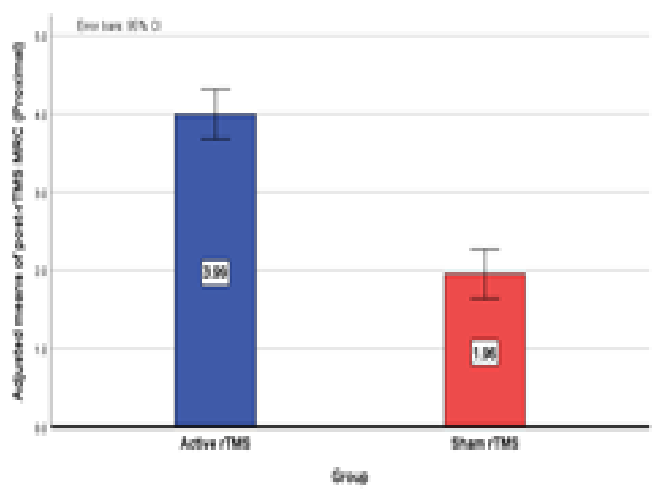

(D)

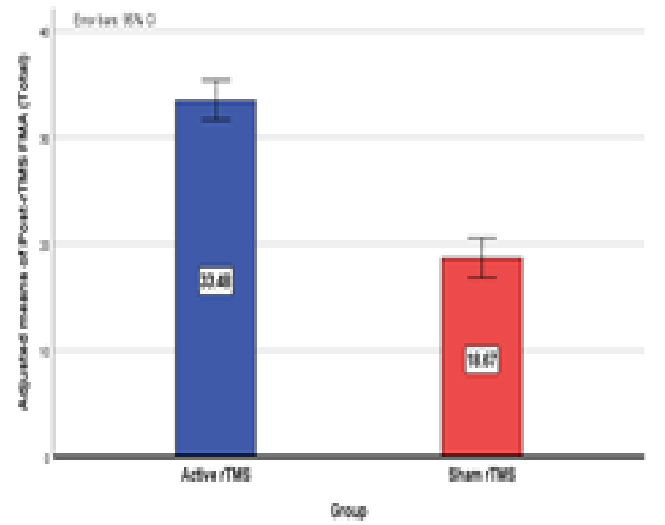

(F)

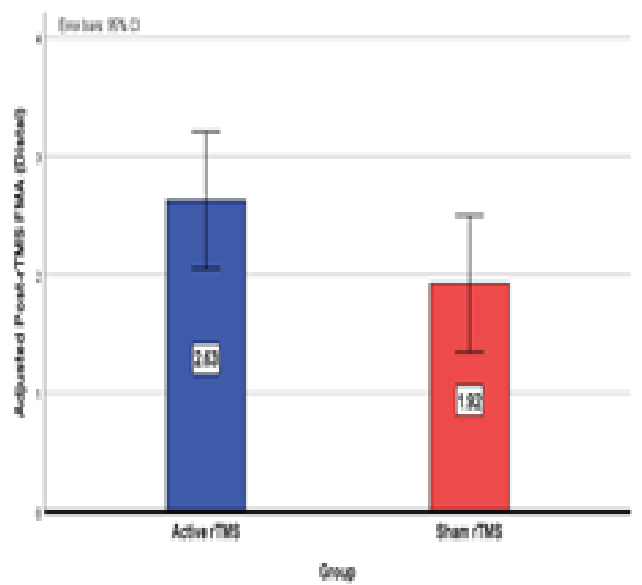

Figure (1) Comparison of adjusted mean of post-rTMS means of (A) mean distal MRC; (B) mean proximal MRC; (C) grand mean MRC; (D) distal UEFMA; (E) proximal UE-FMA; (E) total UE-FMA of the affected side 
Table (4): Comparisons of Post-rTMS motor assessment (MRC and UE-FMA) in the study groups after adjustment for pre-rTMS scores, using one-way ANCOVA

\begin{tabular}{|c|c|c|c|c|c|c|}
\hline \multirow{2}{*}{\multicolumn{2}{|c|}{$\begin{array}{l}\text { Assessment } \\
\text { Measures }\end{array}$}} & \multicolumn{2}{|c|}{ Adjusted post-rTMS means } & \multirow[b]{2}{*}{$F$ value } & \multirow[b]{2}{*}{$P$ value } & \multirow[b]{2}{*}{$\begin{array}{c}\text { Partial } \\
\eta^{2}\end{array}$} \\
\hline & & $\begin{array}{c}\text { Active rTMS } \\
\text { group }\end{array}$ & $\begin{array}{c}\text { Sham rTMS } \\
\text { group }\end{array}$ & & & \\
\hline \multirow{3}{*}{ MRC } & $\begin{array}{l}\text { Mean } \\
\text { distal }\end{array}$ & $1.49 \pm 0.04$ & $1.33 \pm 0.04$ & 6.380 & 0.016 & 0.147 \\
\hline & $\begin{array}{l}\text { Mean } \\
\text { proximal }\end{array}$ & $3.99 \pm 0.16$ & $1.96 \pm 0.16$ & 85.551 & $<0.0005$ & 0.698 \\
\hline & $\begin{array}{l}\text { Grand } \\
\text { mean }\end{array}$ & $2.73 \pm 0.09$ & $1.76 \pm 0.09$ & 56.093 & $<0.0005$ & 0.603 \\
\hline \multirow{3}{*}{$\begin{array}{l}\text { UE- } \\
\text { FMA }\end{array}$} & $\begin{array}{l}\text { Total } \\
\text { distal }\end{array}$ & $2.63 \pm 0.29$ & $1.92 \pm 0.29$ & 3.030 & 0.090 & 0.076 \\
\hline & $\begin{array}{l}\text { Total } \\
\text { proximal }\end{array}$ & $31.24 \pm 0.79$ & $16.35 \pm 0.76$ & 169.915 & $<0.0005$ & 0.821 \\
\hline & Total & $33.48 \pm 0.92$ & $18.67 \pm 0.92$ & 130.331 & $<0.0005$ & 0.779 \\
\hline
\end{tabular}

Relationship between baseline severity of motor impairment and post-rTMS improvement:

Relaying on the bimodal balancerecovery model, we assumed that patients with more severe motor impairment might have better improvement after cPMd facilitation with high frequency TMS. Therefore, the stepwise regression analysis was done within the active rTMS group, using the baseline grand mean MRC of the disabled UE and baseline

(A)

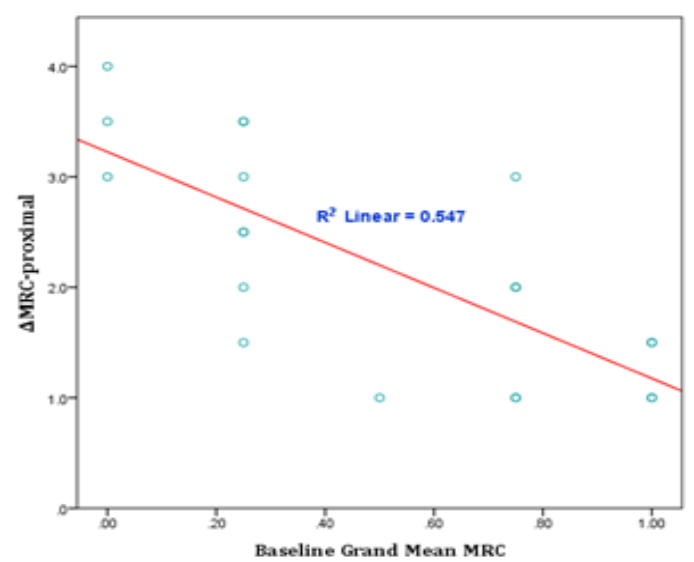

TMS-induced MEPs amplitudes of iM1 as independent variables, and post-rTMS improvement in the disabled UE proximal motor functions as dependent variables. Post-rTMS improvement (change scores) in the mean proximal MRC and the proximal UE-FMA was defined as the post-rTMS minus pre-rTMS scores, and were referred to as $\triangle \mathrm{MRC}$-proximal and $\triangle$ FMA-proximal respectively. Multicollinearity among the independent variables was excluded by VIF of 1 .

(B)

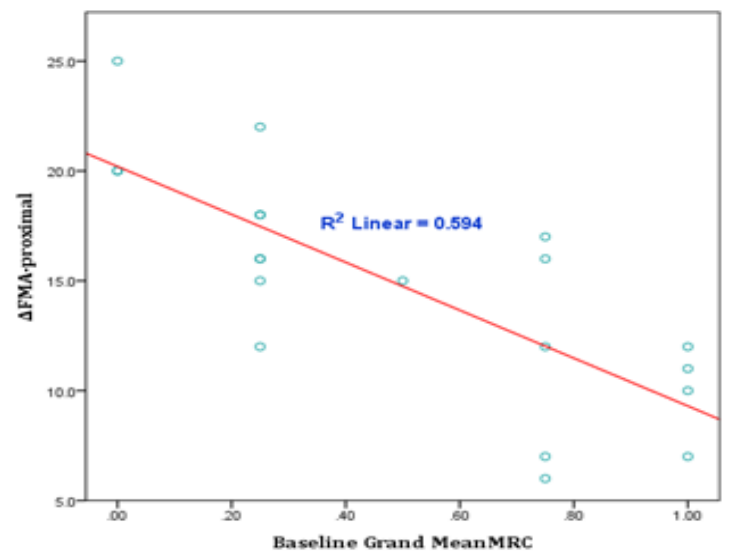

Figure (2): Relationship between baseline grand mean MRC of the disabled UE and (A) $\triangle M R C$-proximal; (B) $\triangle F M A$-proximal 
Pearson correlation revealed significant negative correlations between baseline grand mean MRC of the disabled UE from one side and $\triangle \mathrm{MRC}$-proximal $(\mathrm{r}=-0.740$, $\mathrm{P}<0.01)$ and $\triangle$ FMA-proximal $(\mathrm{r}=-0.771$, $\mathrm{P}<0.01)$ from the other side (Figure. 2).

(A)

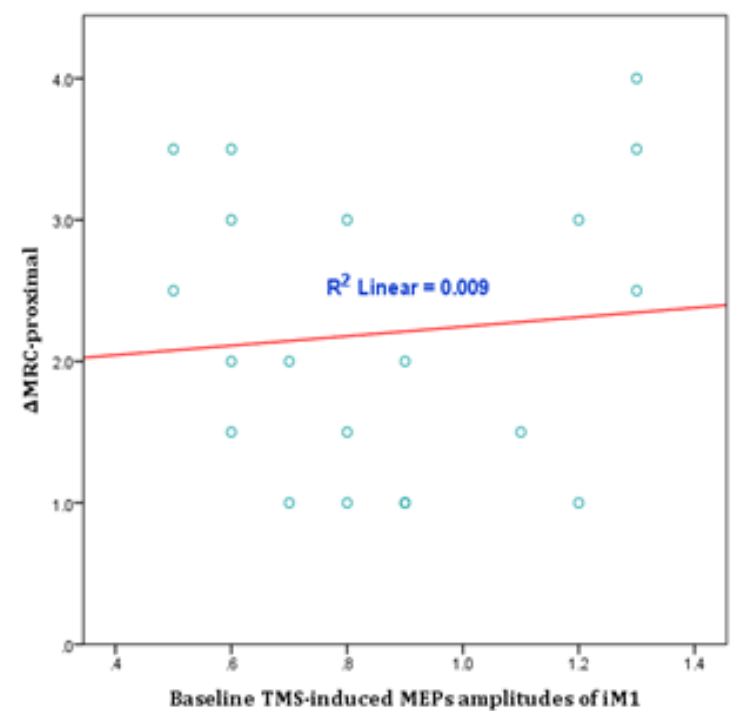

Conversely, no significant correlation was found between baseline TMS-induced MEPs amplitudes of iM1 from one side and neither $\triangle$ MRC-proximal $(\mathrm{r}=0.092$, $\mathrm{P}=0.699)$ nor $\triangle \mathrm{FMA}$-proximal $(\mathrm{r}=0.175$, $\mathrm{P}=0.462$ ) from the other side (Figure. 3 ).

(B)

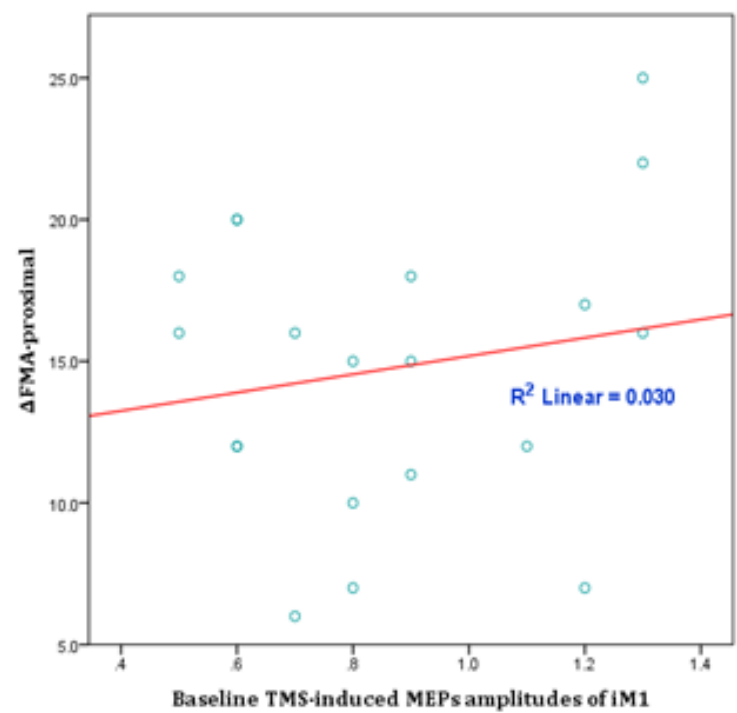

Figure (3): Relationship between baseline TMS-induced MEPs amplitudes of iM1 and (A) $\triangle M R C$-proximal; (B) $\triangle F M A-p r o x i m a l$

Stepwise multivariate regression revealed that lower grand mean MRC of the disabled UE is independent predictor of better post-rTMS improvement in proximal functions of the disabled UE (higher $\triangle \mathrm{MRC}$-proximal and $\triangle \mathrm{FMA}$ - proximal), whereas baseline TMS-induced MEPs amplitudes of iM1 is not predictive for neither $\triangle \mathrm{MRC}$-proximal nor $\triangle \mathrm{FMA}$ proximal, and it was removed by the analysis. (Table 5)

Table (5): Stepwise regression analysis of $\triangle \mathrm{MRC}$-proximal and $\Delta \mathrm{MRC}$-proximal within the active rTMS group

\begin{tabular}{|c|c|c|c|}
\hline Observations & Predictor & Beta & $P$-value \\
\hline$\Delta \mathrm{MRC}$-proximal & $\begin{array}{c}\text { baseline grand } \\
\text { mean MRC }\end{array}$ & -2.050 & $<0.001$ \\
$\left(\mathrm{R}^{2}=0.547 ; \mathrm{F}_{(1,18)}=21.753 ; P<0.001\right)$ & $\begin{array}{c} \\
\text { baseline grand } \\
\text { mean MRC }\end{array}$ & $-10,900$ & $<0.001$ \\
$\left(\mathrm{R}^{2}=0.594 ; \mathrm{F}_{(1,18)}=26.373 ; P<0.001\right)$ & & \\
\hline
\end{tabular}




\section{DISCUSSION}

The present study found that cPMd facilitation, using high frequency rTMS, improved the disabled UE motor functions of severely impaired stroke survivors, particularly the proximal functions. The lower degree of motor power of the disabled UE was an independent predictor of better post-rTMS improvement in the proximal motor power and performance of the disabled UE.

These results were consistent with a recently released crossover trial, while our study was still going on (Sankarasubramanian et al., 2017). They found that facilitation of cPMd was associated with better improvement in severely disabled patients, while the traditional approach was associated with more improvement in mildly disabled patients. The cutoff of severity that separates between the candidates for the tradition approach vs. cPMd facilitation was identified as Fractional Anisotropy (FA) of 0.5 and UE-FMA (proximal) of 26-28.

For more understanding of the role of contralesional hemisphere in post-stroke motor control of the paretic UE in patient with low structural reserve, two trials examined the perturbation effect of applying TMS to different contralesional motor areas on proximal reaching movement of the paretic UE. Mohapatra et al. (2016) have found that applying TMS to cM1 or cPMd during the period between a "Go" cue and the onset of reaching movement was associated with significant increase in reaching movement time, as well as decreased peak velocity, acceleration and movement smoothening regardless of which area was stimulated.
Harris-Love and Harrington (2017) have found that the effect of contralesional TMS perturbation on proximal reaching movement of the paretic UE is greater in patients with poor structural reserve, particularly when applied to cPMd. These findings supported the results of the present study and the assumption that contralesional hemisphere, particularly cPMd, has a compensatory role in severely impaired patients.

The reported improvement in motor functions of the paretic limb after cPMd facilitation might be attributed to alleviation of the IHI. Two trials found that applying high frequency rTMS to cPMd generated more reduction in ipsilateral silent period, or less IHI imposed on $\mathrm{iM} 1$, in more severely impaired patients, whereas no significant reduction was reported in patients with mild impairment (Sankarasubramanian et al., 2017 and Liao et al., 2019). The other mechanism that could explain our findings is increased connectivity of ipsilateral motor pathways to the paretic limb. There is evidence from previous experiments that the ipsilateral motor pathways control the paretic limb following brain insults through uncrossed pyramidal projections and alternate motor fibers. Therefore facilitation of contralesional motor areas could positively influence the ipsilateral motor output to paretic UE. The structural and functional connectivity of the ipsilateral corticospinal pathway were studied by using diffusion tensor imaging (DTI) and TMS-EMG respectively. It has been found that stroke patients have increased structural and functional connectivity of the ipsilateral corticospinal pathway to the paretic limb, and this increase was higher in patient with more 
severe motor impairment (Jayaram et al., 2012). Post-stroke increased connectivity of contralesional pathway includes not only corticospinal tract, but also the alternate motor pathways. Rüber et al. (2012) have reported post-stroke increased integrity of the ipsilateral cortico-rubrospinal pathway to the paretic limb as measured by DTI.

While the previous data has shown that the traditional inhibition of cM1 could worsen the bimanual coordination, another very recently released crossover trial found that post-stroke facilitation of cPMd was associated with improving bimanual coordination in severe cases, while mildly impaired patients were improved with traditional iM1 facilitation (Liao et al., 2019).

We did not report any adverse effects after repetitive facilitation of cPMd. While the risk of seizure, which is the most serious side of effect of rTMS, is extremely rare, it has been found that this risk increases with stroke preexistence. Additionally, the risk of seizures varies according to the stimulation site. It has been reported that facilitation of the M1 carries a higher risk of seizures (67\% of the reported seizures) than facilitation of prefrontal areas $(29 \%$ of the reported seizures) (Lerner et al., 2019). So the novel technique that includes PMd facilitation might be associated with a lower risk of seizures. Another probable advantage of our technique is avoiding rTMS application ipsilesionally, which may add additional risk of seizure. Future studies using rTMS-EEG are needed to compare the EEG changes that may result from facilitation of ipsilesional versus contralesional motor areas.
We selected right handed patients with non-dominant cerebral infarctions to avoid poor communication and bias that could occur with cortical manifestations, such as aphasia, in dominant hemisphere strokes. The other important concern is that handedness might be associated with asymmetric functional connectivity of both hemispheres. It has been reported that right handers have different functional interhemispheric connectivity and hemispheric asymmetries of brain networks in relation to left handers (Raemaekers et al., 2018).

The present study was restricted to severe cases. This did not allow us to detect the cutoff points for applying facilitatory vs. inhibitory NIBS to the contralesional motor areas. Further studies, including wide range of severity, are needed to define the poor structural reserve accurately in three axes; clinical severity, structural integrity using DTI, and functional motor output using TMSEMG.

\section{CONCLUSION}

Applying high frequency rTMS to cPMd can improve motor functions of the paretic UE, mainly proximal functions, in more severely impaired stroke patients. Future studies are needed to explain our findings and to accurately define the severity cutoff for facilitation vs. inhibition of contralesional motor areas with rTMS.

\section{DISCLOSURE}

The authors declared that no potential conflicts of interest concerning this paper to be disclosed and they did not receive financial support from any third party. 


\section{REFERENCES}

1. Alawieh A, Tomlinson S, Adkins D, Kautz $S$ and Feng W (2017): Preclinical and Clinical Evidence on Ipsilateral Corticospinal Projections: Implication for Motor Recovery.Transl Stroke Res., 8(6): 529-540.

2. Boddington LJ and Reynolds JNJ (2017): Targeting interhemispheric inhibition with neuromodulation to enhance stroke rehabilitation. Brain Stimul., 10 (2): 214-222.

3. Cunningham DA, Potter-Baker KA, Knutson JS, Sankarasubramanian V, Machado AG and Plow EB (2015): Tailoring Brain Stimulation to the Nature of Rehabilitative Therapies in Stroke A Conceptual Framework Based on Their Unique Mechanisms of Recovery. Phys Med Rehabil Clin N Am., 26 (4):759-74.

4. Di Pino G, Pellegrino G, Assenza G, Capone F, Ferreri F, Formica D, Ranieri F, Tombini M, Ziemann U, Rothwell JC and Di Lazzaro V (2014): Modulation of brain plasticity in stroke: a novel model for neurorehabilitation. Nat Rev Neurol., 10 (10): 597-608.

5. Finisguerra A, Borgatti $\mathbf{R}$ and Urgesi $\mathbf{C}$ (2019): Non-invasive Brain Stimulation for the Rehabilitation of Children and Adolescents With Neurodevelopmental Disorders: A Systematic Review. Front Psychol. Feb; 6 (10):135.

6. Genç E, Ocklenburg $S$, Singer $W$ and Güntürkün O (2015): Abnormal interhemispheric motor interactions in patients with callosal agenesis. Behav Brain Res., 15; (293):1-9.

7. Gorelick PB (2019): The global burden of stroke: persistent and disabling. Lancet Neurol., 18 (5): 417-418.

8. Harris-Love ML and Harrington RM (2017): Non-Invasive Brain Stimulation to Enhance Upper Limb Motor Practice Poststroke: A Model for Selection of Cortical Site.Front Neurol., 29(8): 224.

9. Hatem SM, Saussez G, Della Faille M, Prist V, Zhang X, Dispa D and Bleyenheuft Y (2016): Rehabilitation of Motor Function after Stroke: A Multiple Systematic Review Focused on Techniques to Stimulate Upper Extremity Recovery. Front Hum Neurosci., 13(10): 442.

10. Hendricks HT, van Limbeek J, Geurts AC and Zwarts MJ (2002): Motor recovery after stroke: a systematic review of the literature. Arch Phys Med Rehabil., 83 (11): 1629-37.

11. Hübers A, Böckler $B$ and Kammer $T$ (2019): Ipsilateral cortical silent period as a marker of corpus callosum function in amyotrophic lateral sclerosis. Brain Stimulation Journal., 12 (2): 400.

12. Jayaram G, Stagg CJ, Esser P, Kischka U, Stinear J and Johansen-Berg $H$ (2012): Relationships between functional and structural corticospinal tract integrity and walking post stroke. Clin Neurophysiol., 123(12): 2422-8.

13. Lee YY, Hsieh YW, Wu CY, Lin KC and Chen CK (2015): Proximal Fugl-Meyer Assessment Scores Predict Clinically Important Upper Limb Improvement After 3 Stroke Rehabilitative Interventions. Arch Phys Med Rehabil., 96 (12): 2137-44.

14. Lerner AJ, Wassermann EM and Tamir D (2019): Seizures from transcranial magnetic stimulation 2012-2016: Results of a survey of active laboratories and clinics. Clin Neurophysiol., 130 (8): 1409-1416.

15. Liao WW, Whitall J, Wittenberg GF, Barton JE and McCombe Waller S (2019): Not all brain regions are created equal for improving bimanual coordination in individuals with chronic stroke. Clin Neurophysiol., 130 (8): 1218-1230.

16. Mohapatra S, Harrington $\mathrm{R}$, Chan $\mathrm{E}$, Dromerick AW, Breceda EY and HarrisLove M (2016): Role of contralesional hemisphere in paretic arm reaching in patients with severe arm paresis due to stroke: A preliminary report. Neurosci Lett., (617): 52-8.

17. Raemaekers M, Schellekens W, Petridou N and Ramsey NF (2018): Knowing left from right: asymmetric functional connectivity 
during resting state. Brain Struct Funct., 223(4): 1909-1922.

18. Rüber $T$, Schlaug $G$ and Lindenberg $R$ (2012): Compensatory role of the corticorubro-spinal tract in motor recovery after stroke. Neurology, 7; 79(6): 515-22.

19. Sankarasubramanian V, Machado AG, Conforto AB, Potter-Baker KA, Cunningham DA, Varnerin NM, Wang X, Sakaie $K$ and Plow EB (2017): Inhibition versus facilitation of contralesional motor cortices in stroke: Deriving a model to tailor brain stimulation. Clin Neurophysiol., 128 (6): 892-902.
20. Takeuchi N, Tada T, Matsuo $Y$ and Ikoma K (2012): Low-frequency repetitive TMS plus anodal transcranial DCS prevents transient decline in bimanual movement induced by contralesional inhibitory rTMS after stroke. Neurorehabil Neural Repair, 26 (8): 988-98.

21. Walcott BP, Miller JC, Kwon CS, Sheth SA, Hiller M, Cronin CA Schwamm LH, Simard JM, Kahle KT, Kimberly WT and Sheth KN (2014): Outcomes in severe middle cerebral artery ischemic stroke. Neurocrit Care, 21 (1): 20-6. 


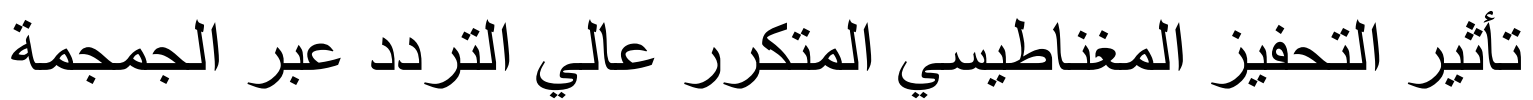

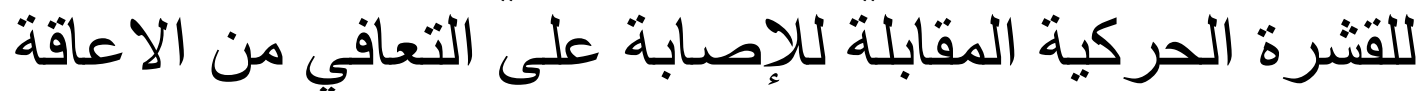
الحركية الثديدة بعد السكتة الدماغية لإهية

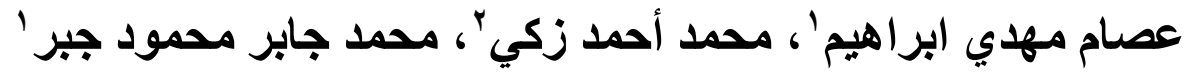
قسم طب المخ و الأعصاب، كلية طب الأزهر دمياط'، القاهرة'، مصر

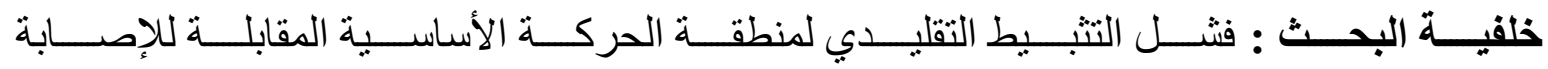

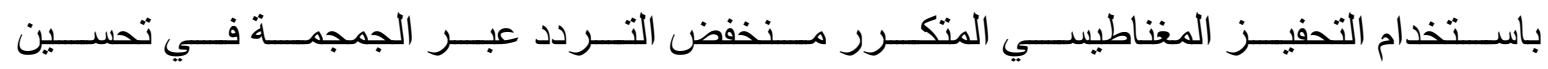

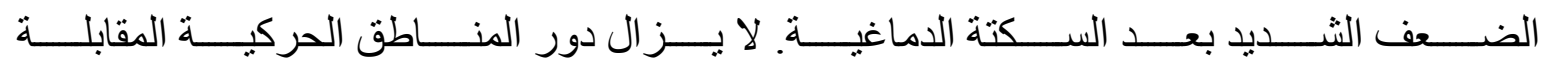

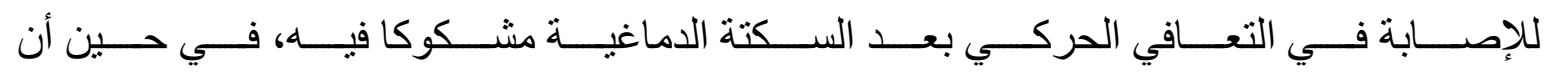

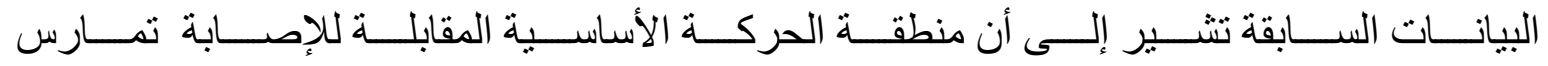

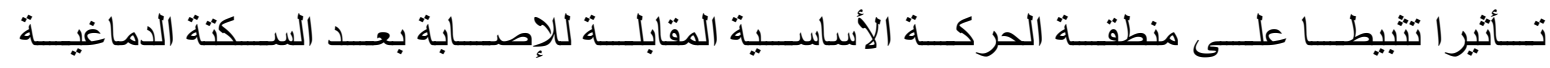

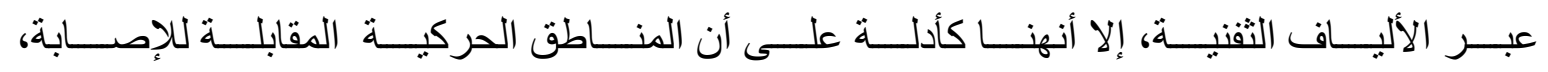

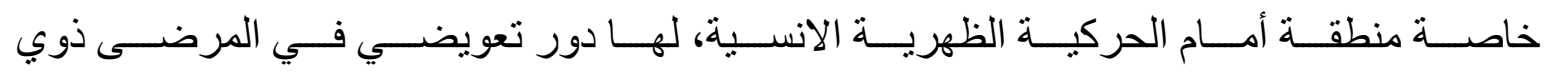
الإعاقات الثنديدة و التلف الممتد بجهة الاصابة.

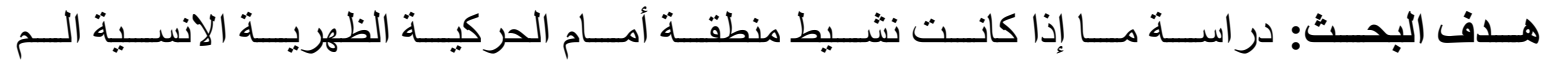

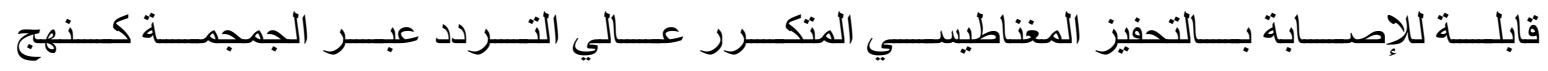

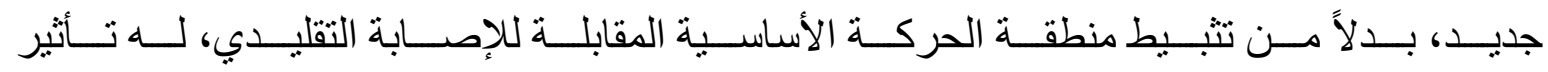

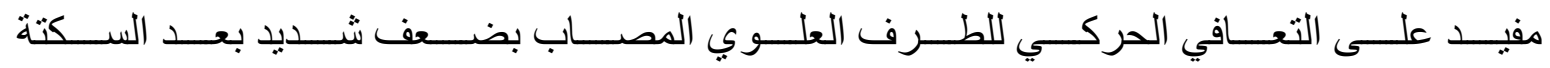
الاماغية أم لا.

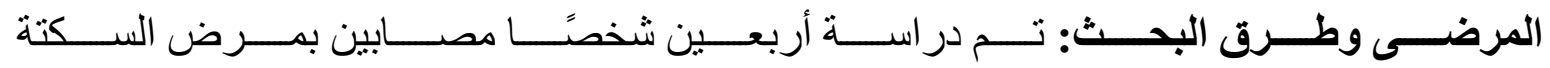

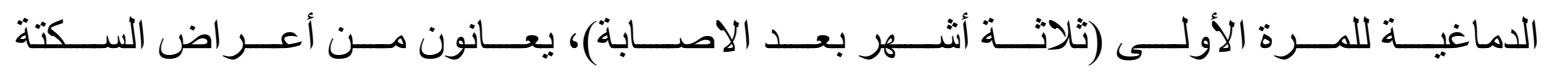

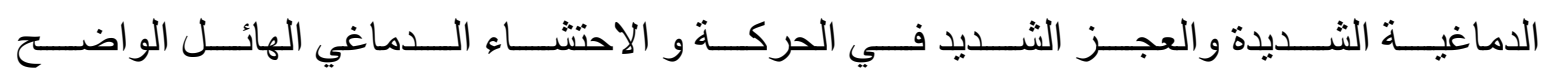

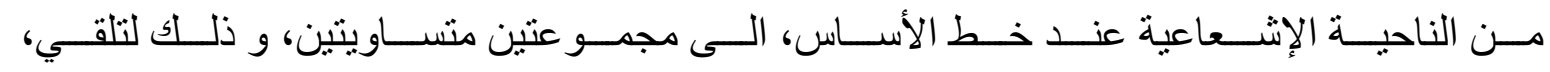

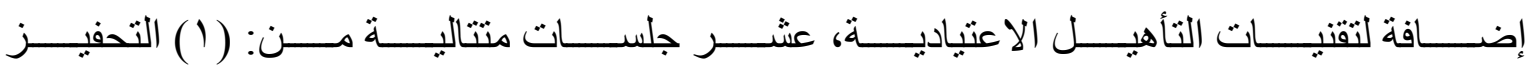

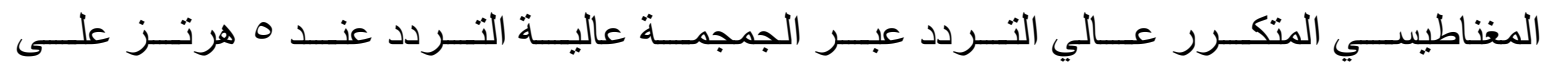

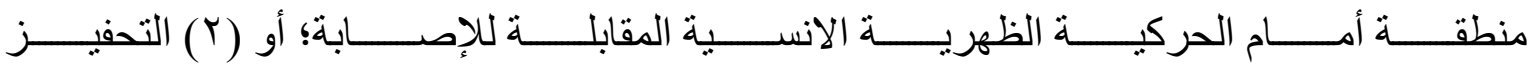




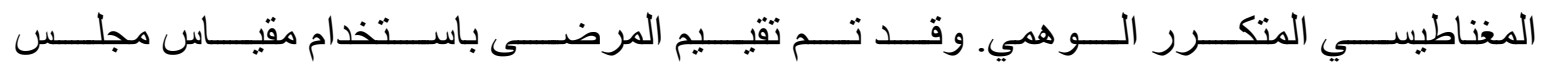
البحوث الطبية لقوة العضلات و تقييم فيجل ماير قبل و بعد التدخل.

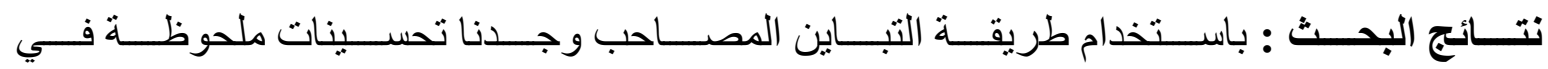

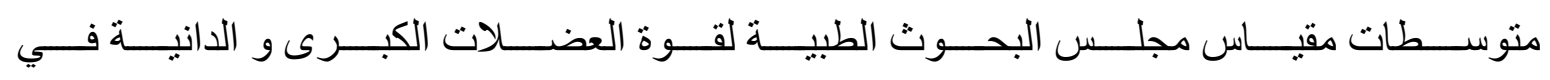

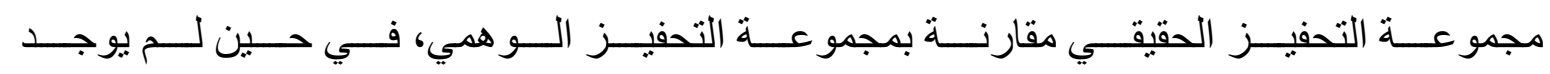

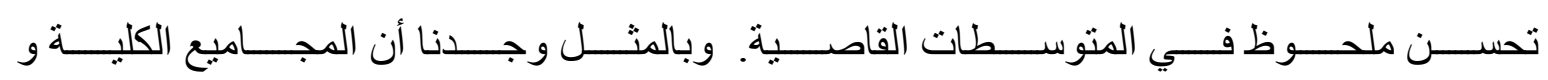

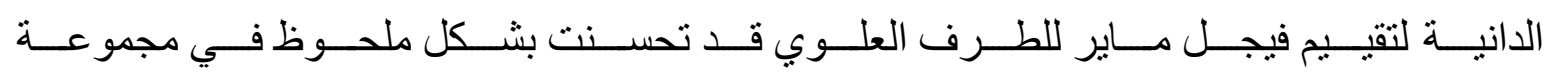

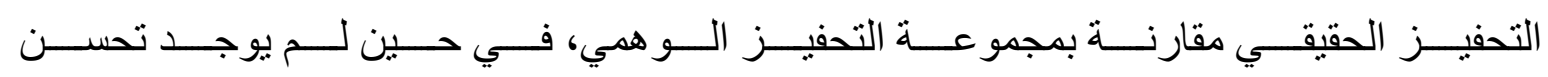

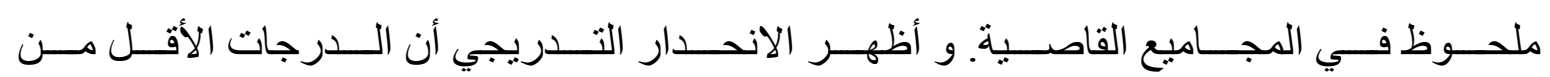

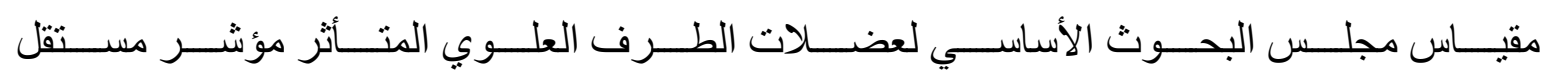
على استجابة أفضل لنهج التحفيز المغناطيسي المتكرر عبر الجمجمة الجديد.

الاســتنتاج: يمكـن أن يــؤدي تتشــيط القتـــرة أمـــام الحركيــة الظهريـــة الانســية بالجانــبـ

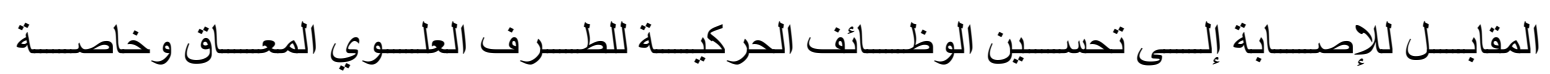
الوظائف الدانية لدى مرضى السكتة الدماغية الأشد اعتلالا. 